\title{
Non-muscle invasive bladder cancer cystoscopic surveillance: from overuse to underuse and non-adherence impact
}

\author{
Leonardo O. Reis \\ UroScience and Department of Urologic Oncology, Pontifical Catholic University of Campinas (PUC-Campinas), São Paulo, Brazil \\ Correspondence to: Leonardo O. Reis, MD, PhD. UroScience and Department of Urologic Oncology, Pontifical Catholic University of Campinas \\ (PUC-Campinas), Av. John Boyd Dunlop, s/n, Campinas, São Paulo, CEP 13060-904, Brazil. Email: reisleo.1@gmail.com. \\ Provenance: This is an invited article commissioned by the Section Editor Xiao Li (Department of Urology, Jiangsu Cancer Hospital \& Jiangsu \\ Institute of Cancer Research \& Nanjing Medical University Affiliated Cancer Hospital, Nanjing, China). \\ Comment on: Schroeck FR, Lynch KE, Li Z, et al. The Impact of Frequent Cystoscopy on Surgical Care and Cancer Outcomes Among Patients With \\ Low-Risk, Non-Muscle-Invasive Bladder Cancer. Cancer 2019;125:3147-54.
}

Submitted Sep 12, 2019. Accepted for publication Sep 24, 2019.

doi: $10.21037 /$ tau.2019.10.05

View this article at: http://dx.doi.org/10.21037/tau.2019.10.05

The burden of non-muscle-invasive bladder cancer (NMIBC) surveillance is well known, including $8 \%$ surgical complication with up to $3 \%$ death, adding to anxiety, discomfort and health care expenditures (1-4).

Schroeck et al. found in a low-grade Ta (AJCC) NMIBC retrospective cohort study that compared to guidelines recommended ( 1 to 3 cystoscopies) surveillance, patients that underwent frequent cystoscopies ( $>3, \mathrm{n}=798,77 \%)$ during the first 2 years after diagnosis had significantly doubled the transurethral resections (TUR) with no impact on bladder cancer progression and death (3\% at 5 years) (5).

On the other hand, a subtle and contradicting result obtained in the same data blows the mind of the most attentive readers: after sensitivity analysis for intermediaterisk disease, earlier muscle-invasive progression or mortality significantly occurred among those with more than recommended surveillance (3\% at 4.0 years $v s .3 \%$ at 6.2 years; HR 2.13; 95\% CI, 1.06-4.27) (5) and it is likely because of unobserved confounding such as tumor size, multifocality, early and frequent recurrence, which were neglected in the study and may put patients at a higher risk warranting high-risk similar approach (6).

Moreover, about $60 \%$ of NMIBC are considered intermediate or high risk based on pathology, representing the bulk of a continuum (7). Also in the high-risk spectrum of the NMIBC, Datovo et al. recently described $18 \%$ of cystoscopy non-adherence in the first 3 years of followup and among potential related factors (disease and patient characteristics and behaviors) and eventual consequences, cystoscopy non-adherence was significantly associated with less urinary cytology and $2.33 \mathrm{HR}$ for progression, (95\% CI, 1.18-4.59) (8).

While the need for frequent and costly cystoscopic surveillance is thought to be the main NMIBC cost burden, Mossanen et al. comparing expenditures across risk categories using mathematical modeling found that while cystoscopy contributes to considerable expenses, disease progression to MIBC was the primary cost driver, mainly in the high-risk disease (9).

In fact, the data comparing different surveillance regimens for NMIBC are limited, with relatively short follow-up and very underpowered, warranting further refinement and acknowledgement of the natural heterogeneity of NMIBC (10-12).

While it looks undisputable that the main forces driving the surveillance frequencies in the real world are related to the attending physician choices, usually based on identification of perceptive risk factors, part of chronic unobserved confounding in retrospective studies, patients also interfere by cystoscopy non-adherence (8) or by demanding a very high level of sensitivity before they would be willing to accept an alternative to cystoscopy for surveillance (13).

The above-mentioned paradigm shifting studies illustrate a boiling arena and promissory future with clear potential for clinical and economic optimizations, refining care 
quality and sustainability (14).

Cystoscopic surveillance is still the gold standard strategy to the inherently highly recurrent and naturally heterogenic NMIBC and depending on surveillance intensity, it might be accountable not only for impacting on disease control, but for costs ranging from potentially unnecessary procedures, anxiety, discomfort and health care expenditures in one of the most expensive cancers from diagnosis to death.

The lack of data regarding ideal follow-up alongside the wide NMIBC spectrum and its impact makes the topic very important, instigating future studies to improve surveillance and to further understand cystoscopy overuse, underuse and adherence.

\section{Acknowledgments}

Funding: The study was supported by "National Council for Scientific and Technological Development"-CNPq, Brazil, Research Productivity (304747/2018-1).

\section{Footnote}

Conflicts of Interest: The author has no conflicts of interest to declare.

Ethical Statement: The author is accountable for all aspects of the work in ensuring that questions related to the accuracy or integrity of any part of the work are appropriately investigated and resolved.

\section{References}

1. Hollenbeck BK, Miller DC, Taub D, et al. Risk factors for adverse outcomes after transurethral resection of bladder tumors. Cancer 2006;106:1527-35.

2. Gregg JR, McCormick B, Wang L, et al. Short term complications from transurethral resection of bladder tumor. Can J Urol 2016;23:8198-203.

3. Matulewicz RS, Sharma V, McGuire BB, et al. The effect of surgical duration of transurethral resection of bladder

Cite this article as: Reis LO. Non-muscle invasive bladder cancer cystoscopic surveillance: from overuse to underuse and non-adherence impact. Transl Androl Urol 2019;8(Suppl 5):S472-S473. doi: 10.21037/tau.2019.10.05 tumors on postoperative complications: an analysis of ACS NSQIP data. Urol Oncol 2015;33:338.e19-e24.

4. Koo K, Zubkoff L, Sirovich BE, et al. The burden of cystoscopic bladder cancer surveillance: anxiety, discomfort, and patient preferences for decision making. Urology 2017;108:122-8.

5. Schroeck FR, Lynch KE, Li Z, et al. The Impact of Frequent Cystoscopy on Surgical Care and Cancer Outcomes Among Patients With Low-Risk, Non-MuscleInvasive Bladder Cancer. Cancer 2019;125:3147-54.

6. Kamat AM, Witjes JA, Brausi M, et al. Defining and treating the spectrum of intermediate risk nonmuscle invasive bladder cancer. J Urol 2014;192:305-15.

7. Nielsen ME, Smith AB, Meyer AM, et al. Trends in stage-specific incidence rates for urothelial carcinoma of the bladder in the United States: 1988 to 2006. Cancer 2014;120:86-95.

8. Datovo JCF, Neto WA, Mendonça GB, et al. Prognostic impact of non-adherence to follow-up cystoscopy in nonmuscle invasive bladder cancer (NMIBC). World J Urol 2019;37:2067-71.

9. Mossanen M, Wang Y, Szymaniak J, et al. Evaluating the cost of surveillance for non-muscle-invasive bladder cancer: an analysis based on risk categories. World J Urol 2019;37:2059-65.

10. Olsen LH, Genster HG. Prolonging follow-up intervals for non-invasive bladder tumors: a randomized controlled trial. Scand J Urol Nephrol Suppl 1995;172:33-6.

11. Leblanc B, Duclos AJ, Bénard F, et al. Long-term followup of initial Ta grade 1 transitional cell carcinoma of the bladder. J Urol 1999;162:1946-50.

12. Mariappan P, Smith G. A surveillance schedule for G1Ta bladder cancer allowing efficient use of check cystoscopy and safe discharge at 5 years based on a 25 -year prospective database. J Urol 2005;173:1108-11.

13. van Osch FHM, Nekeman D, Aaronson NK, et al. Patients choose certainty over burden in bladder cancer surveillance. World J Urol 2019. [Epub ahead of print].

14. Reis LO. Non-muscle invasive bladder cancer (NMIBC): boiling arena and promissory future. World J Urol 2019;37:1999-2000. 